\title{
PENURUNAN MUTUAL COUPLING ANTENA MIMO MENGGUNAKAN PERIODIK DEFECTED GROUND STRUCTURE U-SHAPE
}

\author{
Liska Ammai ${ }^{1}$, Levy Olivia Nur ${ }^{2}$, Radial Anwar ${ }^{3}$ \\ ${ }^{1,2}$ Fakultas Teknik Elektro, Universitas Telkom \\ ${ }^{3}$ Fakultas Ilmu Terapan, Universitas Telkom \\ 1 ammailiska@student.telkomuniversity.ac.id, ${ }^{2}$ levyolivia@telkomuniversity.ac.id , \\ 3 radialanwar@tass.telkomuniversity.ac.id
}

\begin{abstract}
Abstrak
Pada penelitian ini, peningkat performansi antena mikrostrip MIMO dilakukan dengan menggunakan efek mutual coupling, maka dengan pencacatan bidang groundplane, atau yang biasa disebut dengan metode defected ground structure (DGS). Bentuk DGS yang digunakan adalah U-shape dan terbukti dapat mengurangi efek mutual coupling pada antena MIMO mencapai -22,833 dB dibandingkan dengan antena konvensional. Dengan menggunakan hingga 2 periodik, U-shape juga berhasil diperoleh pengurangan dimensi antena mencapai $29,89 \%$ dibandingkan dengan dimensi antena MIMO konvensional. Hal ini tentunya terbukti membuat metode DGS sesuai untuk digunakan pada antena dengan dimensi yang kecil dan mutual coupling yang baik pada massive MIMO pada aplikasi di perangkat portable.
\end{abstract}

Kata Kunci: defected ground structure (DGS); antena mikrostrip; U-shape; mutual coupling

\section{Abstract}

In this research work. The performance of microstrip MIMO antenna is improved by mutual coupling by defecting the field of the groundplane, also commonly referred as defected ground structure (DGS) method. The shape of DGS used is U-shape and phas been proved to reducing the mutual coupling effect on the MIMO antenna, reaching up to $-22,833 \mathrm{~dB}$ compared to conventional antenna. By using 2 periodic U-shapes, also managed to obtain a reduction of antenna dimensions reaching $\mathbf{2 9 , 8 9 4 \%}$ compared to conventional MIMO antenna dimensions. It is proven that the DGS method suitable for use on antennas with small dimensions and the massive MIMO because it is suitable to reduce the mutual coupling effect on applications for portable devices.

Key Words: defected ground structure (DGS); microstrip antenna; - shape; mutual coupling;

\section{Pendahuluan}

Dalam teknologi microwave, antena mikrostrip banyak digunakan pada akses radio untuk mobile and wireless communication, satellite, radar dan millimeter wave communication. Salah satu teknologi antena terbaru adalah Multiple Input Multiple Output (MIMO). Teknologi ini telah menjadi bagian yang krusial pada sistem komunikasi nirkabel generasi ke-4 (4G). Fitur yang paling signifikan dari teknologi MIMO adalah dapat meningkatkan kapasitas saluran tanpa menambah bandwidth maupun peningkatan daya transmisi. Namun, terdapat kelemahan pada antena MIMO yaitu dibutuhkan isolation port antar patch yang tinggi dan ukuran yang tidak sederhana untuk aplikasi di perangkat portable.

Ada beberapa metode yang dapat digunakan untuk mengatasi permasalah pada antena mikrostrip MIMO ini.
Salah satunya yaitu metode Defected Ground Structure (DGS) yang cukup popular karena dianggap strukturnya yang mudah untuk dibuat [1]. DGS adalah salah satu metode yang digunakan pada antena mikrostrip dengan merusak struktur pada bagian groundplane antena. Bentuk struktur yang digunakan baik satu bentuk ataupun beberapa bentuk pada groundplane tetap dianggap sebagai DGS [1]. Pada saat ini, DGS digunakan untuk berbagai macam aplikasi termasuk pada antena mikrostrip untuk meningkatkan bandwidth antena [2]-[3] untuk mendapatkan nilai mutual coupling yang baik pada antena array dan MIMO [4]-[5] untuk memperkecil dimensi ukuran antena mikrostrip [6]-[7].

Pada penelitian ini, dilakukan analisis perbandingan bentuk DGS pada antena mikrostrip konvensional dengan antena DGS bentuk $U$-shape. 
Antena konvensional dan antena DGS akan memiliki frekuensi kerja yang sama dan bentuk patch yang sama. Dalam perancangannya, patch yang digunakan adalah rectangular, sedangkan frekuensinya adalah $3650 \mathrm{MHz}$ yaitu menggunakan frekuensi dari aplikasi WiMAX serta nilai standar lain untuk parameter kerja antena mikrostrip secara umum.

\section{Multiple Input Multiple Output (MIMO)}

Sistem MIMO digunakan pada komunikasi seluler, khususnya dimulai dari generasi 4G. Hal ini dikarenakan MIMO sangat membantu mengurangi terjadinya multipath fading, di mana fading tersebut bisa terjadi karena sinyal melalui rute-rute yang berbeda serta mengalami pemantulan maupun blocking oleh obstacle yang dilalui [5]. Dalam menyusun antena MIMO, perlu diperhatikan apakah akan disusun memanjang atau susunan lainnya. Antar antena juga harus diberikan jarak sepanjang d baik secara vertikal maupun horizontal agar meminimalkan isolasi dan tidak terjadi kebocoran data dari satu antena ke antena yang lainnya.

\section{Antena Mikrostrip}

Berdasarkan IEEE Standard Definitions of Terms of Antenna, antena diartikan sebagai sebuah alat yang dapat memancarkan dan menerima gelombang radio [6]. Dalam kata lain, antena merupakan sebuah perangkat transisi yang menghubungkan antara ruang bebas dengan pemandu gelombang. Struktur antena terdiri dari tiga lapisan yaitu paling bawah adalah groundplane, lalu ditengah adalah substrat dan lapisan paling atas adalah patch, Sementara itu, kekurangan dari antena mikrostrip yaitu memiliki gain yang lebih kecil, bandwidth yang sempit, serta radiasi yang berlebihan pada pencatuan [8].Berdasarkan uraian tersebut, maka penulis menentukan pilihan pada penggunaan antena mikrostrip sebagai antena yang digunakan dikarenakan memiliki bentuk yang relatif kecil dan dapat dimodifikasi serta mampu bekerja pada frekuensi tinggi.

\section{Defected Ground Structure}

Defected Ground Structure (DGS) adalah suatu cara menekan gelombang permukaan dengan cara menghilangkan (etch) sebagian bidang ground. DGS merujuk pada geometri ukuran yang disebut unit sel yang merupakan satu bentuk bangun yang diletakkan pada groundplane dari microwave printed circuit board (M-PCB) yang bertujuan agar menghentikan gelombang elektromagnetik pada layer substrat sepanjang frekuensi operasi dari antena. Perbedaan bentuk dan ukuran DGS pada frekuensi operasi akan memberi perbedaan pada bentuk rangkaian penggantinya sesuai dengan daerah yang defected [9].

\subsection{Satu Sel DGS}

Satu sel DGS adalah satu geometri DGS yang mudah dan sederhana pada bidang groundplane. Geometri DGS yang termasuk bentuk yang sederhana adalah persegi dumbbell [4], [10], bentuk $U$-shape [11] dan lain-lain. Terdapat pula bentuk yang lebih kompleks yaitu complementary split ring resonator [5]. Bentuk DGS di implementasikan pada filter, pada antena mikrostrip, dan pada aplikasi microwave lainnya.

\subsection{Periodik DGS}

Pengulangan dari satu unit DGS yang terdapat pada bidang groundplane dapat membantu mendapatkan karakteristik stopband yang lebih baik. Dengan demikian, bentuk DGS yang mengalami pengulangan dari satu unit DGS dapat disebut sebagai periodik DGS. Untuk mendapatkan performansi yang lebih baik seperti bandwidth dan menekan ripples dapat menggunakan struktur DSG berbentuk non-periodic. Bentuk periodik DGS dapat disusun secara arah vertikal ataupun horizontal misalnya pada multi rings with slot [6], [12]. Hal ini dimaksudkan untuk dapat meningkatkan faktor slow-wave pada mikrostrip line dan bentuk waveguide lainnya, hal ini efektif untuk mendapatkan miniaturisasi ukuran antena.

\section{Perancangan Antena}

Untuk merancang suatu antena, diperlukan suatu spesifikasi khusus yang sudah disiapkan sehingga dapat memudahkan proses perancangan dan menjadi acuan dalam pembuatan suatu antena. Jenis antena yang dirancang adalah antenna mikrostrip dengan patch berbentuk rectangular. Spesikasi antena terdapat pada Tabel 1 ditetapkan berdasarkan tujuan perancangan ini yaitu untuk membandingkan nilai mutual coupling menggunakan metode defected ground structure pada antena MIMO. Adapun spesifikasi yang diharapkan dapat tercapai adalah sebagai berikut:

Tabel 1. Spesifikasi Antena Di Rancang

\begin{tabular}{|c|c|}
\hline Frekuensi resonansi & $3,65 \mathrm{GHz}$ \\
\hline Impedansi & $50 \mathrm{~W}$ \\
\hline VSWR & 2 \\
\hline Mutual coupling & $20 \mathrm{~dB}$ \\
\hline
\end{tabular}

\subsection{Pabrikasi Antena MIMO Konvensional}

Setelah setiap variabel dari antena didapat melalui perhitungan, variabel-variabel tersebut kemudian diterapkan untuk merancang antena menggunakan software HFSS 15.0. Simulasi dilakukan untuk menguji 
apakah antena yang berdasarkan hasil perhitungan mencapai spesifikasi yang diinginkan. Apabila belum tercapai, perlu dilakukan optimisasi ukuran dari beberapa variabel antena. Desain pertama adalah antena konvensional MIMO 2x2 patch rectangular, yaitu antena sebelum defected ground structure diletakkan pada bidang groundplane. Selanjutnya dilakukan pabrikasi antena konvensional seperti yang terlihat pada Gambar 1. Antena konvensional hasil pabrikasi ini menggunakan epoxy FR-4 dan cooper sebagai bahannya. Terlihat pada Gambar 2 bahwa bagian belakang antena adalah groundplane yang penuh tanpa tercacati bentuk DGS apapun.

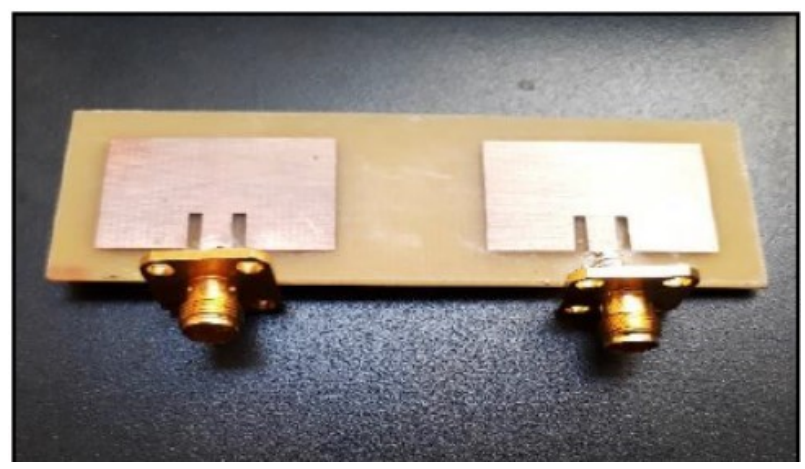

Gambar 1. Antena MIMO konvensional tampak depan (a)

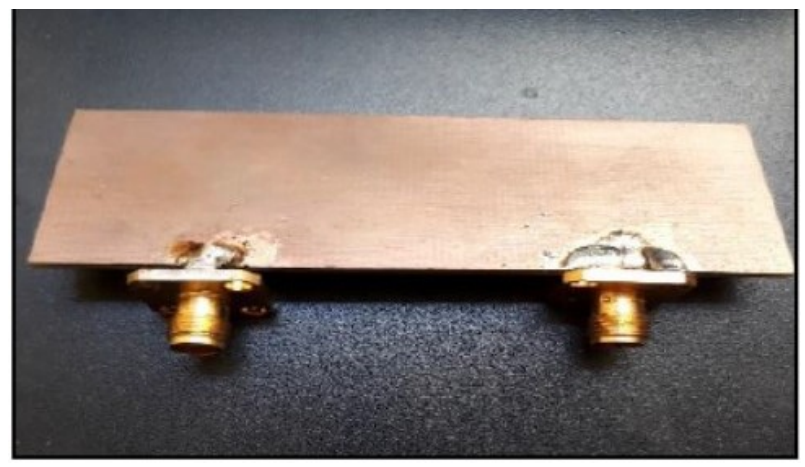

Gambar 2. Antena MIMO konvensional tampak bawah (b)

\subsection{Hasil Pengukuran MIMO Konvensional}

Bentuk antena konvensional MIMO 2x2 dapat dilihat pada Gambar 1 dan untuk nilai maksimum dari jarak pisah patch peradiasi yang digunakan adalah 14 [7]. Hasil pengukuran dari antena hasil pabrikasi dapat dilihat pada Gambar 3 yang menyajikan grafik nilai VSWR. Dari grafik tersebut dapat terlihat bahwa antena hasil pabrikasi telah berada pada puncak frekuensi

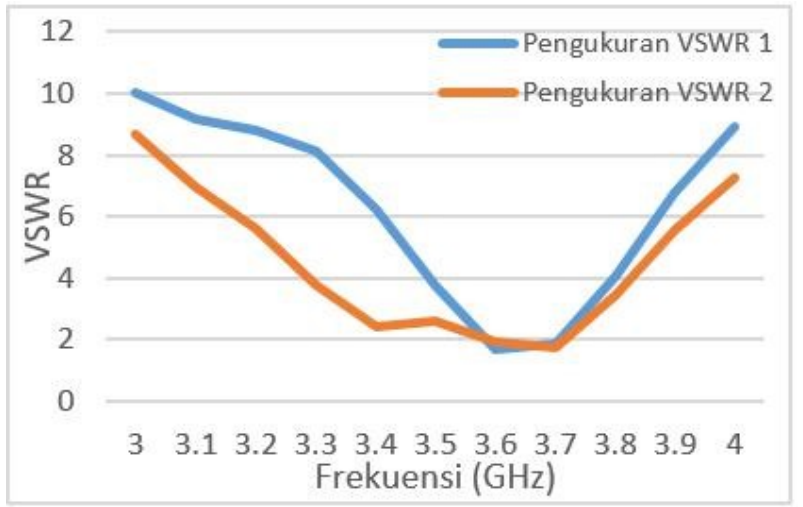

Gambar 3. Grafik perbandingan pengukuran VSWR MIMO konvensional

resonansi yang diharapkan yaitu $3,65 \mathrm{GHz}$ dengan nilai VSWR adalah 1,325 dan 1,382 pada tiap port. Untuk parameter mutual coupling, hasil pengukuran antena pabrikasi disajikan pada Gambar 4. Berdasarkan hasil pengukuran nilai mutual coupling antena pabrikasi, didapatkan nilai sebesar $-19,521 \mathrm{~dB}$ pada port 1 dan $-19,543 \mathrm{~dB}$ pada port 2 dengan jarak 14 . Grafik hasil pengukurannya disajikan pada Gambar 4.

\section{Desain DGS U-Shape}

Setelah mendapatkan antena konvensional, kemudian langkah selanjutnya adalah mendesain DGS $U$-shape pada groundplane antena. Penelitian ini menyajikan analisis pengaruh periodik DGS dengan cara memvariasikan nilai variabel, sehingga didapatkan

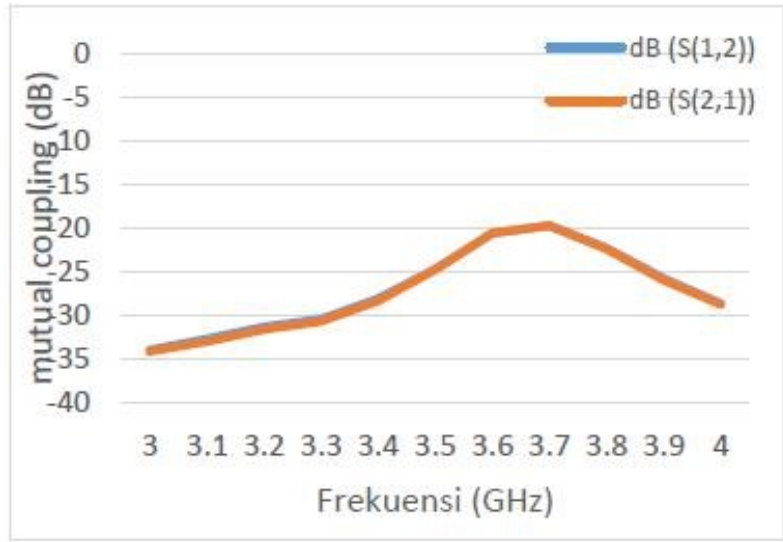

\section{Gambar 4. Grafik perbandingan pengukuran mutual} coupling MIMO konvensional

karakteristik dari bentuk DGS pada penurunan efek mutual coupling. Gambar 56 adalah bentuk desain periodik DGS $U$-shape yang digunakan. Nilai yang menjadi referensi adalah variabel $n$ yang merupakan 
lebar sisi $U$-shape adalah $18 \mathrm{~mm}$, variabel $g$ yaitu lebar gap $U$-shape sebesar $4 \mathrm{~mm}$ dan variabel $m$ adalah tinggi $U$-shape sebesar $20 \mathrm{~mm}$ [11]. Sebelumnya telah dilakukan simulasi dengan memvariasikan dimensi $U$-shape untuk setiap kondisi unit sel DGS dan juga periodik DGS dimana masing -masing hasilnya disajikan pada [12]. Setiap nilai dari variabel pada Gambar 56 divariasikan dengan mengecilkan dan memperbesar nilainya. Ukuran dimensi DGS dibatasi agar tidak melebihi dimensi groundplane. Desain dengan penurunan puncak frekuensi paling besar adalah dengan menggunakan nilai masing masing variabelnya yaitu $n$ sebesar $8 \mathrm{~mm}, \mathrm{~m}$ sebesar $10 \mathrm{~mm}$ dan $\mathrm{g}$ adalah $1 \mathrm{~mm}$. Nilai parameter telah memenuhi standar sehingga desain inilah yang kemudian dipilih untuk dilakukan iterasi dan digunakan pada antena MIMO.

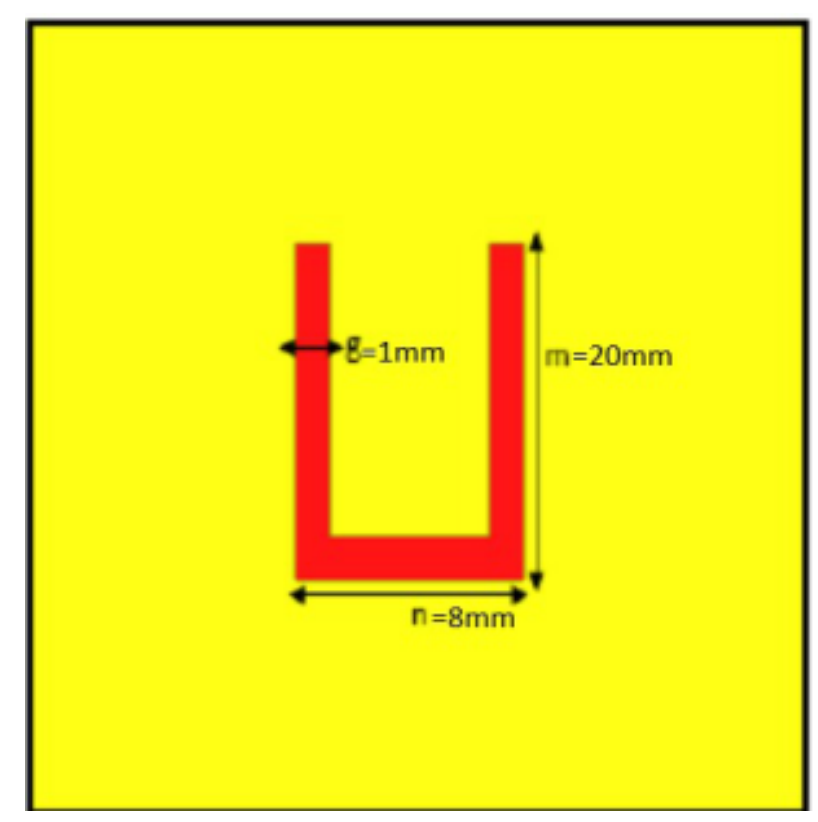

Gambar 5. Desain sel dan periodik DGS $U$-shape (a)

\subsection{Desain Antena Periodik DGS U-Shape}

Pada simulasi dimensi optimasi, diperoleh hasil yang paling maksimal adalah dengan menggunakan periodik dua defected ground structure U-shapes. Dimensi dari $U$-shape yang digunakan diambil dari dimensi hasil optimasi dimana setiap nilai variabel pada $U$-shape sebelumnya telah di variasikan dengan memperkecil dan memperbesar nilainya. Ketika sebelumnya telah didapatkan dimensi antena MIMO konvensional yang telah memenuh persyaratakan dan kemudian didapatkan dimensi DGS $U$-shape yang paling optimum selanjutnya adalah mendesain 2 DGS $U$-shapes pada bagian groundplane antena MIMO seperti terlihat pada Gambar 78.

Pada sistem antena MIMO dimensi antena sangat bergantung pada jarak pisah antar patch peradasi. Jarak

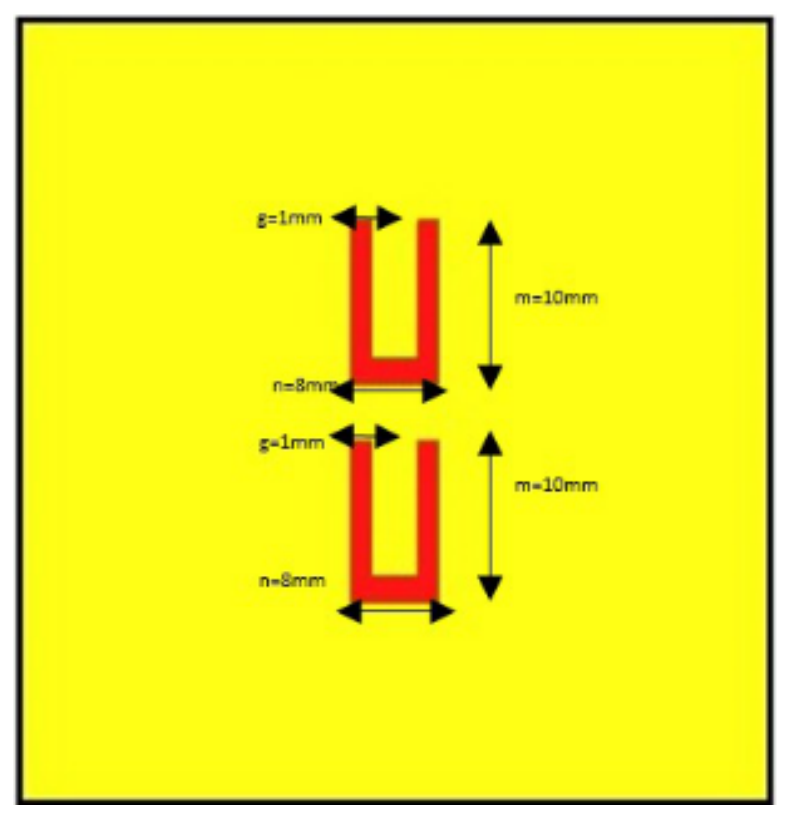

Gambar 6. Desain sel dan periodik DGS $U$-shape (b)

pisah ini dipengaruhi oleh nilai dari mutual coupling pada semua port antena. Semakin jauh jarak pisahnya, maka dimensi antena MIMO akan semakin besar dan begitupun sebaliknya. Dilain sisi, efek mutual coupling akan semakin tidak bagus jika patch peradiasi semakin dekat karena antena akan dengan mudah dapat saling mempengaruhi satu sama lainnya.

Pada penelitian ini, disajikan data hasil perubahan jarak pisah patch peradiasi dari jarak 12 hingga 110 pada antena DGS $U$-shape untuk melihat berapa jarak pisah maksimum antar patch peradasi yang dapat digunakan. Hasil simulasinya dapat dilihat pada Gambar 9.

Nilai standar dari mutual coupling pada antena MIMO adalah -20 $d B$ dimana pada nilai inilah jarak pisah paling maksimum untuk masing masing patch peradiasi. Seperti yang terlihat pada Gambar 9 bahwa

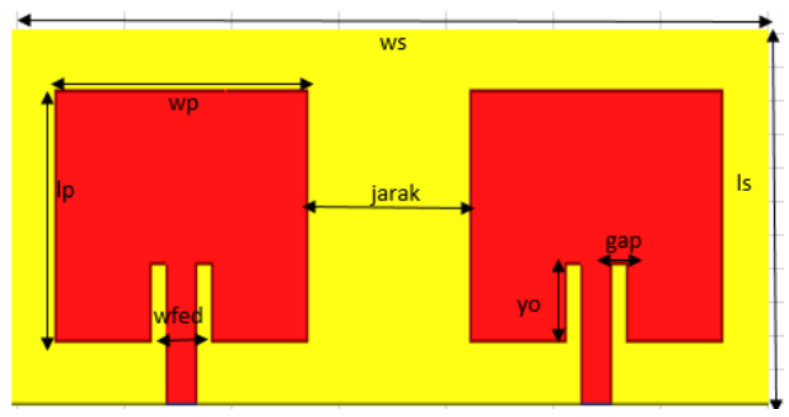

Gambar 7. Desain DGS U shape pada antena MIMO tampak depan (a)

untuk jarak 14 nilai mutual coupling mencapai sebesar $-22,833 d B$ sedangkan ketika mencoba untuk 


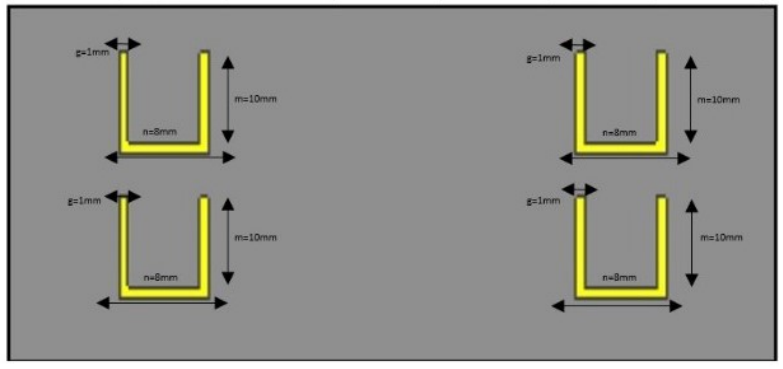

Gambar 8. Desain DGS U-shape pada antena MIMO tampak belakang (b)

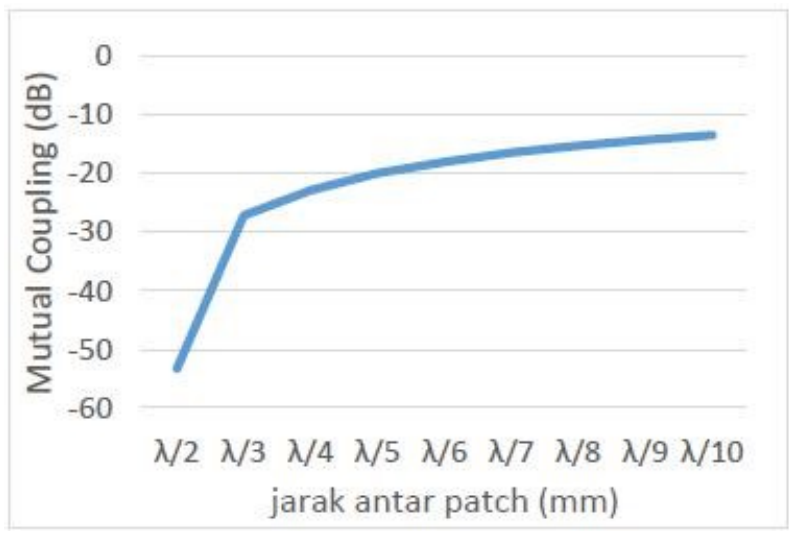

Gambar 9. Mutual coupling DGS MIMO

mendekatkan jarak pisah patch peradasi hingga 15 nilainya telah mencapai angka sebesar $-19,904 d B$ dimana nilai ini sudah tidak memenuhi persyaratan untuk nilai standar mutual coupling. Berdasarkan hasil simulasi antena MIMO konvensional dan antena DGS, diperoleh jarak pisah maksimum dimana nilai mutual coupling masih memenuhi persyaratan yaitu pada 14 . Nilai mutual coupling hasil pabrikasi antena konvensional pada jarak tersebut adalah sebesar $-19,521$ $d B$ dan $-19,543 d B$ sedangkan untuk simulasi antena MIMO U-shape nilai mutual coupling pada jarak yang sama mencapai $-22,833 d B$. Pada hasil ini terlihat bahwa untuk simulasi menggunakan software simulator, antena menggunakan DGS dapat memberikan nilai mutual coupling yang lebih baik daripada antena konvensional tanpa defected ground structure. Pada kedua kondisi ini, antena berada pada frekuensi resonansi yang sama yaitu 3,65 GHz. Selanjutnya, dilakukan pabrikasi antena MIMO $U$-shape untuk melihat hasil pengukuran menggunakan alat ukur.

\subsection{Pabrikasi Antena DGS U-Shape}

Sama halnya pada desain sebelumnya yaitu pada antena konvensional, untuk antena menggunakan DGS, setelah dilakukan desain pada software simulator selanjutnya akan diamati juga dari pengukuran antena hasil pabrikasi. Antena DGS U-shape yang dicetak adalah yang merupakan hasil paling optimal dengan kondisi jarak pisah patch yang sama yaitu 14 dengan dua periodik $U$-shapes setelah sebelumnya pada Gambar 9 disajikan pengaruh jarak pisahnya. Antena yang dicetak menggunakan bahan epoxy FR-4 sebagai substrak dan cooper pada bagian patch dan groundplane. Antena yang telah dicetak kemudian diukur untuk melihat nilai parameter dalam antena seperti pada antena konvensional sebelumnya. Antena DGS $U$-shape hasil pabrikasi terlihat pada Gambar 10.

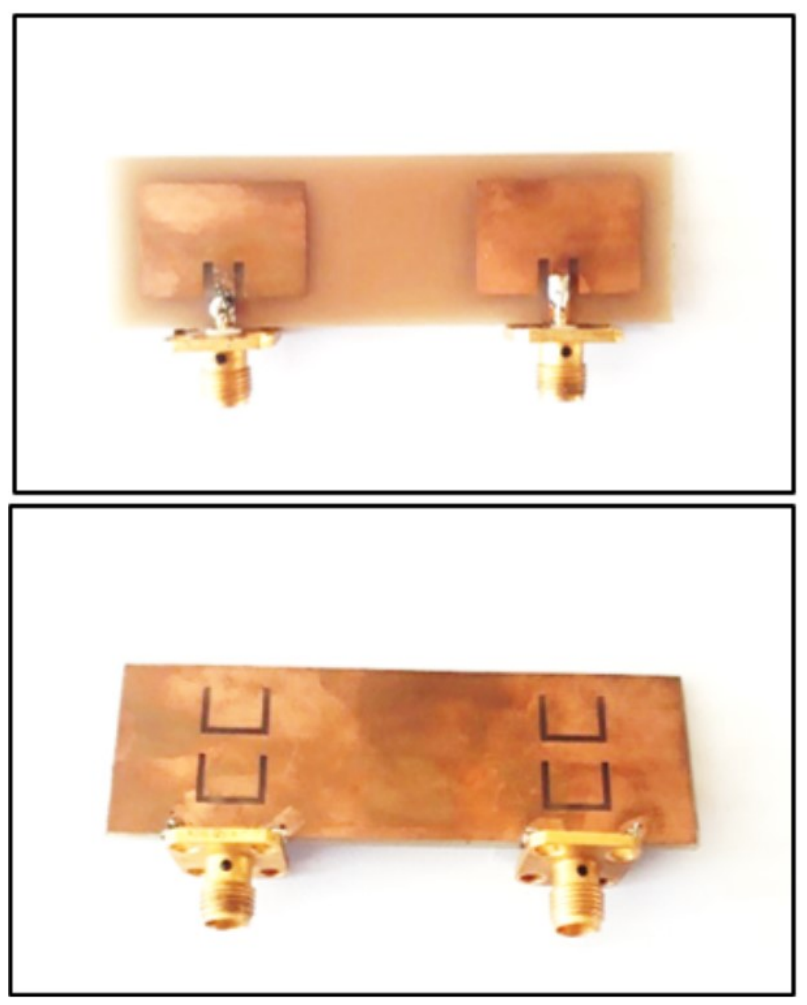

\section{Gambar 10. Antena DGS U shape pabrikasi tampak depan (atas) dan tampak belakang (bawah)}

\section{Hasil Pengukuran DGS U-Shape}

Antena DGS yang telah dipabrikasi selanjutnya diukur menggunakan Network Analyzer untuk melihat beberapa parameter kerja antena seperti frekuensi puncak resonansi, nilai VSWR dan mutual coupling. Selanjutnya nilai hasil pengukuran setiap parameter ini akan diperbandingkan dengan hasil pengukuran antena MIMO konvensional.

Grafik hasil pengukuran yang pertama adalah pada parameter frekuensi resonansi dan VSWR yang disajikan pada grafik Gambar 11. Perbandingan nilai VSWR antena untuk masing masing port 1 dan 2 . Terlihat pada 


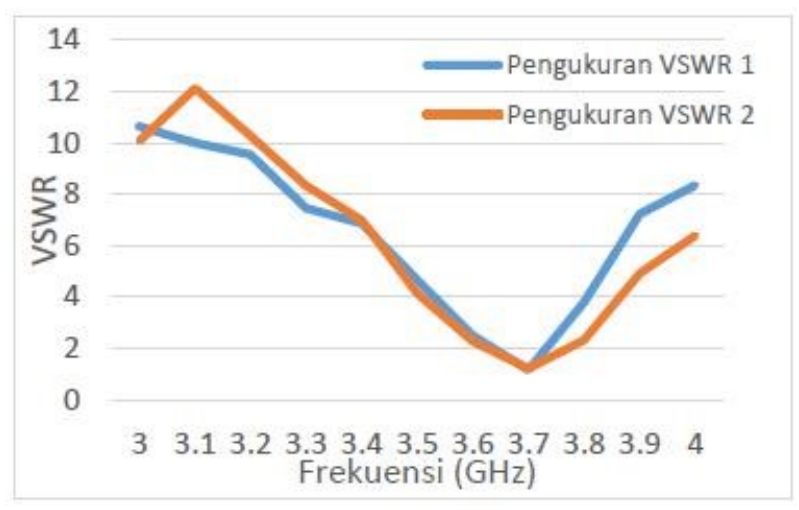

\section{Gambar 11. Grafik pengukuran VSWR U-shape MIMO}

Gambar 11 bahwa antena MIMO DGS U-shape hasil pabrikasi telah berada pada puncak frekuensi $3,65 \mathrm{GHz}$ dengan nilai VSWR pada port 1 adalah 1,67 dan 1,60 pada port 2. Nilai ini telah memenuhi persyaratan yaitu dibawah 12. Sedangkan untuk nilai parameter mutual coupling grafiknya disajikan pada Gambar 12. Grafiknya terdiri dari perbandingan nilai mutual coupling antara antena port 1 dan antena port 2 hasil pengukuran. Terlihat pada Gambar 11 bahwa antena MIMO DGS

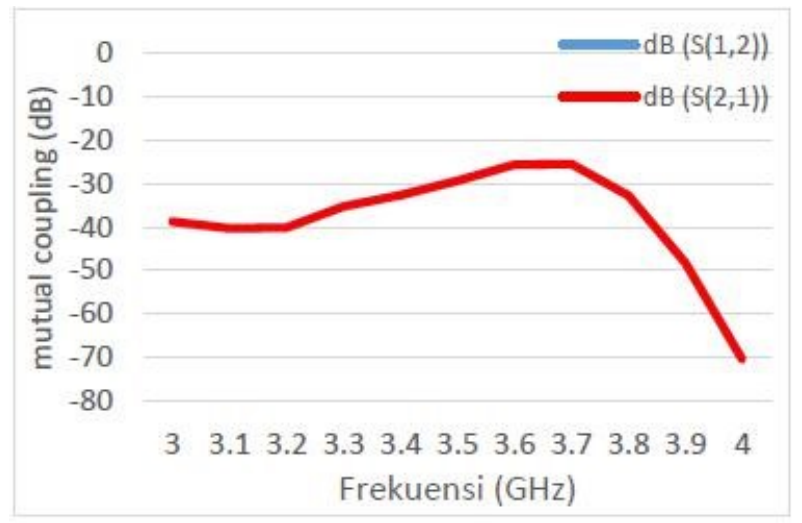

\section{Gambar 12. Grafik pengukuran mutual coupling U-shape MIMO}

$U$-shape pada simulasi dan pabrikasi dengan jarak pisah patch peradiasi adalah 14 menghasilkan nilai yang masing masing garis menunjukkan angka yang masih memenuhi nilai standar pada frekuensi yang diharapkan yaitu 3,65 GHz. Pada pengukuran antena hasil pabrikasi yaitu sebesar $-22,833 \mathrm{~dB}$. Hal ini menunjukkan bahwa pada pengukuran, antena telah memenuhi spesifikasi yang diinginkan yaitu pada jarak pisah paling kecil dengan nilai mutual coupling lebih kecil sama dengan $-20 \mathrm{~dB}$. Untuk parameter kerja antena lainnya, seperti puncak frekuensi kerja yang sama, nilai VSWR maupun coupling antena konvensional dan hasil pabrikasi telah memenuhi persyaratan.

\section{Analisis Pengaruh Mutual Coupling Pada Antena DGS}

$U$-shape tersusun sedemikian rupa pada bagian belakang groundplane antena dan berada diantara pusat dari masing-masing patch peradasi. Konfigurasi dengan menggunakan dua $U$-shapes ini memastikan penekanan dari medan listrik terpolarisasi vertikal (gelombang ruang) antara dua patch. Koefisien transmisi antara dua patch peradiasi ditentukan untuk mengukur efek mutual coupling. Karena substrat tidak terlalu tebal, membuat bidang ruang gelombang pada substrak dengan medan listrik vertikal di atas groundplane ketika ini terjadi membuat distribusi arus permukaan pada groundplane salah satu antena sementara antena lainnya tetap pada impedansi awalnya yaitu $50 \mathrm{~W}$.

Pengurangan efek mutual coupling menjadi lebih baik dimungkinkan karena kemampuan $U$-shape yang tersusun vertikal secara periodik untuk secara efisien mampu menekan gelombang listrik ke groundplane antena, yang pada akhirnya secara bergiliran akan mengurangi arus permukaan di patch antena peradiasi

Untuk melihat dengan jelas pengaruh DGS yang dapat memberikan efek penurunan mutual coupling pada antena MIMO, disajikan Gambar 13, yang memperlihatkan nilai mutual coupling antena konvensional dengan antena DGS $U$-shape hasil pabrikasi yang memiliki frekuensi kerja yang sama yaitu pada 3,65 GHz. Semua antena memiliki nilai yang sama untuk mutual coupling pada port 1 dan port 2 pada semua jenis antena.

Terlihat pada Gambar 13 bahwa dengan menggunakan DGS pada antena MIMO dapat memberikan efek yang baik pada mutual coupling antena. Dengan DGS ini, antena pada jarak pisah yang sama dan dimensi yang lebih kecil dapat memiliki performansi kerja yang jauh lebih baik daripada antena konvensionalnya.

\section{Kesimpulan}

Antena MIMO menggunakan metode DGS terbukti dapat meningkat performansi antena. Parameter mutual coupling pada antena DGS memiliki nilai yang lebih baik mencapai nilai sebesar -25,019 dB pada jarak pisah 14 antara dua patch peradiasi. Selain memberikan efek yang baik pada mutual coupling, dengan menggunakan metode DGS ini dimensi antena yang lebih rendah, juga menawarkan yakni penurunan sebesar $n 29,894 \%$ dari dimensi antena konvensional. Hal ini tentunya terbukti membuat metode DGS cocok untuk digunakan pada antena dengan dimensi yang kecil dan mutual coupling yang baik pada massive MIMO untuk aplikasi perangkat portable. 


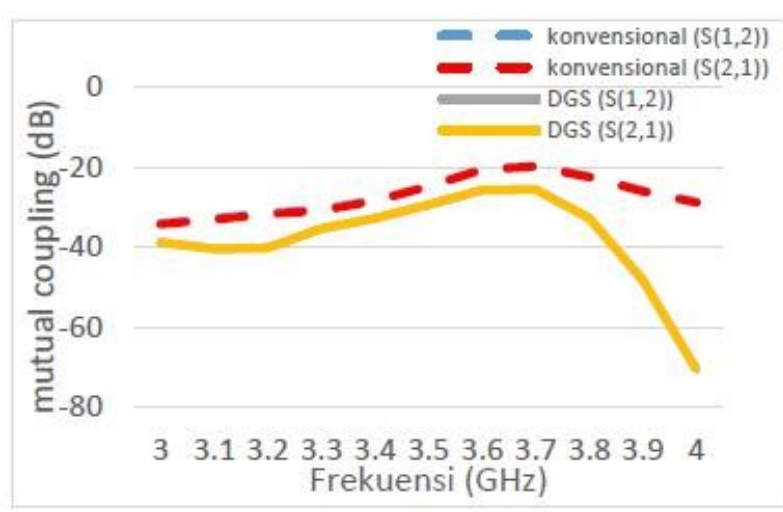

\section{Gambar 13. Grafik perbandingan mutual coupling konvensional dan U-shape MIMO}

\section{Daftar Pustaka}

[1] M. K. Khandelwal, B. K. Kanaujia, and S. Kumar, "Defected ground structure: fundamentals, analysis, and applications in modern wireless trends," International Journal of Antennas and Propagation, vol. 2017, 2017.

[2] C. Aanandan, A. Abbosh, M. Abdallah, M. AbouKhousa, G. Addamo, A. Ahmadi, O. Ahmed, L. Ahumada, A. Akbarzadeh, J. Akkermans et al., "2008 index ieee antennas and wireless propagation letters vol. 7," IEEE Antennas and Wireless Propagation Letters, vol. 7, p. 811, 2008.

[3] D. S. Marotkar and P. Zade, "Bandwidth enhancement of microstrip patch antenna using defected ground structure," in 2016 International conference on electrical, electronics, and optimization techniques (ICEEOT). IEEE, 2016, pp. 1712-1716.

[4] S. S. Khade and S. Badjate, "Square shape mimo antenna with defected ground structure," in 2018 4th International Conference on Recent Advances in Information Technology (RAIT). IEEE, 2018, pp. $1-5$.

[5] M. M. Bait-Suwailam, O. F. Siddiqui, and O. M. Ramahi, "Mutual coupling reduction between microstrip patch antennas using slottedcomplementary split-ring resonators," IEEE Antennas and Wireless Propagation Letters, vol. 9, pp. 876-878, 2010.

[6] L. Ammai, R. Anwar, and D. A. Nurmantris, "Analysis on multi rings defected ground structure for microstrip antenna miniaturization," in 2017 International Conference on Engineering Technology and Technopreneurship (ICE2T). IEEE, 2017, pp. 1-4.

[7] L. AMMAI, "Miniaturisasi antena mikrostrip menggunakan defected ground structure pada frekuensi fixed wimax $3.65 \mathrm{ghz}, " 2017$.

[8] C. A. Balanis, Antenna theory: analysis and design. John wiley \& sons, 2015.

[9] M. Sabran, S. Rahim, M. Yusof, A. Eteng, M. Nor, and I. Ibrahim, "Miniaturized proximity coupled antenna with slot ring as defected ground structure," in 2014 IEEE Symposium on Wireless Technology and Applications (ISWTA). IEEE, 2014, pp. 8185.

[10] M. I. Ahmed, A. Sebak, E. A. Abdallah, and H. Elhennawy, "Mutual coupling reduction using defected ground structure (dgs) for array applications," in 201215 International Symposium on Antenna Technology and Applied Electromagnetics. IEEE, 2012, pp. 1-5.

[11] K. Wei, J.-Y. Li, L. Wang, Z.-J. Xing, and R. Xu, "Mutual coupling reduction of microstrip antenna array by periodic defected ground structures," in 2016 IEEE 5th Asia-Pacific Conference on Antennas and Propagation (APCAP). IEEE, 2016, pp. 389390.

[12] R. Anshari, L. O. Nur, and B. Syihabuddin, "Analisis antena mikrostrip mimo $8 \times 8$ dengan patch berbentuk segitiga pada frekuensi $15 \mathrm{ghz}$," eProceedings of Engineering, vol. 6, no. 2, 2019. 